\title{
US Counties Terminology
}

National Cancer Institute

\section{Source}

National Cancer Institute. US Counties Terminology. NCI Thesaurus. Code C111076.

A list of all the counties in the United States, and the states in which they are located. 